\title{
A TRANSFORMAÇÃO JURÍDICA NA ÓTICA DA FILOSOFIA TRANSMODERNA: A LEGITIMIDADE DOS NOVOS DIREITOS
}

\author{
Celso Ludwig*
}

RESUMO: A transformação jurídica ocorre de diversas maneiràs, como atestam os processos históricos de produção do Direito. A argumentação parte do explícito princípio crítico da obrigação de produzir, reproduzir e desenvolver a vida humana concreta de cada sujeito em comunidade. A vida humana, na condição de critério-fonte, não aparece no nível bem abstrato, não como um direito, mas como fonte de todos os direitos. Propõe-se o tema da transformação jurídica, a partir da premissa de uma fundamentação principiológica, não-metafísica, que encontra no campo ético o primeiro grau de abstração com os princípios éticos implícitos, e em grau menos abstrato encontra o campo político, também com princípios políticos implícitos, e que metodologicamente subsume o nível anterior, para por fim situar o campo jurídico, que é visto no nível dos princípios universais e abstratos; no nível particular das mediações sistêmicas e no nível da ação concreta. A partir desses níveis, a reflexão sobre a transformação do direito ante os novos direitos é encaminhada. Ao final, pretende-se definir a dupla função do Direito: de um lado, sua função é de conservar a vida onde ela está afirmada; e de outro, a função é de transformar onde a vida está negada, na ótica de uma racionalidade jurídica libertadora.

\section{INTRODUÇÃO: MARCOS TEÓRICOS}

De maneira resumida, pretendo expor algumas reflexões e hipóteses gerais acerca da transformação do sistema direito. A estratégia argumentativa procura situar o

\footnotetext{
* Doutor em Direito. Professor em Filosofia do Direito na UFPR.
}

tema no amplo contexto das perspectivas filosóficas, em cotejo com os grandes paradigmas da filosofia ocidental e também com os grandes projetos de mundo, para depois, acentuar os campos do ético, do político e do jurídico. A proposta arquitetônica do tema será apenas indicativa porque um tratamento mais analítico ultrapassaria o objetivo e o limite deste artigo. 
É possível dizer que a filosofia, no Ocidente, desenvolveu quatro ${ }^{1}$ grandes perspectivas de compreensão da realidade, cada uma com sua determinação específica: a perspectiva cosmológica (o ponto de partida e limite é o cosmos - fysis), a teocêntrica (Deus é a origem e o sentido), a antropocêntrica (o princípio e o ponto de chegada é a subjetividade humana) e a biocêntrica (a dinâmica está na complexidade dos sistemas vivos - teia da vida - e na interdependência profunda de todos os fenômenos).

O primeiro critério da demarcação teórica proposta situa o tema na perspectiva antropocêntrica - redefinida paradigmaticamente -, e, sem perder de vista as importantes contribuições $\mathrm{da}$ perspectiva biocêntrica, no reconhecimento da centralidade da complexidade, ressaltada pelo pensamento sistêmico.

Um segundo critério de demarcação teórica situa o tema no contexto da análise paradigmática. Habermas lembra do costume de se "aplicar à história da filosofia o conceito de paradigma, oriundo da história da ciência, e dividir as épocas históricas com o auxílio de ser, consciência e linguagem". ${ }^{2}$ Justo reclamo provém da Filosofia da Libertação, no sentido da inclusão de um quarto paradigma, denominado por Dussel paradigma da vida concreta de cada sujeito

1 Até há pouco tempo falava-se das primeiras três grandes perspectivas da Filosofia. Creio que agora a 4." Perspectiva, a biocêntrica, chamada também de perspectiva ecocêntrica, ecológica ou ainda de perspectiva holística, já faz parte dessa classificação.

2 HABERMAS, J. Pensamento Pós-metafísico. Rio de Janeiro: Tempo Brasileiro, 1990, p.21-22. como modo de realidade - ou paradigma da vida concreta. Com essa inclusão, a divisão das épocas históricas da filosofia ficaria sugerida com o auxílio de ser, consciência, linguagem e vida concreta. Essa mudança paradigmática deve, no entanto, ser entendida no sentido da suprassunção (Aufhebung) hegeliana, ${ }^{3}$ e não na ótica de um processo natural de simples extinção das teorias precedentes substituídas pelas novas. Nesse quadro da filosofia, a demarcação teórica do nosso tema indica uma argumentação que será paradigmática, e a escolha recai sobre o paradigma da vida concreta de cada sujeito como modo de realidade.

Por fim, o terceiro critério de demarcação teórica leva em conta o projeto de mundo que está em jogo. Ao atual debate entre modernidade e pós-modernidade, desejo acrescentar que a produção teórica em geral sobre o assunto traz também orientações tanto de um projeto pré-moderno (são as inúmeras tentativas filosóficas, por exemplo, que tentam reconstruir o sistema-mundo desde as premissas da filosofia do ser) quanto orientações no sentido de um projeto transmoderno - particularmente proposto pelo pensamento contra-hegemônico e pelas filosofias da libertação. ${ }^{4}$ Aqui, nosso tema

3 APEL, Karl-Otto. Fundamentação última nãometafísica. Dialética e liberdade. Petrópolis: Vozes, 1993 , p.320.

4 Quero me referir aos grandes projetos da modernidade, da pós-modernidade e da transmodernidade. Em geral, a polêmica fica reduzida ao projeto da modernidade - que com seu caráter emancipatório aposta nas grandes utopias e promessas de igualdade, liberdade e paz, e a contrapartida da pós-modernidade, descrente das grandes narrativas e que Boaventura 
será construído tendo em vista o horizonte do projeto transmoderno.

Portanto, o lugar arquitetônico do tema fica demarcado no contexto da perspectiva antropocêntrica, situado nos fundamentos e limites do paradigma da vida concreta de cada sujeito, tendo como horizonte o projeto da transmodernidade.

\section{O CRITÉRIO-FONTE: A VIDA HUMANA CONCRETA}

Na opção paradigmática anunciada, a vida concreta de cada sujeito como modo de realidade se constitui como critério fonte, condição de possibilidade de todo o mais. Esse critério - a vida humana - serve como referência de todo ato, norma, estrutura, sistema, subsistema, instituição etc. Assim, a premissa é que a vida humana em comunidade é o modo de realidade do sujeito. A referência ao modo de realidade tem o sentido de tomar a vida humana como ela se apresenta a nós, nas situações concretas do mundo, na idade da globalização e da exclusão. O ser real do modo humano de ser - "seu modo de realidade" - pode fundar-se em juízos

de Sousa SANTOS (2000, p.29, 37) designa por pós-modernidade reconfortante - por não lançar utopias sugere que se aceite e celebre o existente -; posição que contrasta com a pós-modernidade inquietante ou de oposição, esta sim representativa de uma teoria crítica, ainda que pós-moderna porque não subsume sequer o caráter emancipatório da modernidade. O projeto transmoderno tem como ponto de partida as utopias factiveis, criativamente formuladas pelos dissensos legitimamente obtidos nas diversas e heterogêneas comunidades das vítimas, e, ao mesmo tempo, subsume o caráter emancipatório do projeto da modernidade, rejeitando, todavia, seu conteúdo negativo e mítico de justificação de uma práxis irracional e violenta. descritivos, de fato, empíricos, antes de possíveis juízos de valor. E na condição de juízos de fato, esses juízos são constituintes da realidade objetiva que, como tal, é humana. Dessa maneira, a vida humana não é um valor, não é um horizonte ontológico, não é trabalho apenas, não é mera sobrevivência, não se esgota na cultura, não é condição de ser, não se esgota na consciência, não é condição de possibilidade da argumentação, não é só um direito, e não é condição de possibilidade, mas modo de realidade. O existir como modo de realidade do vivente humano é mais do que propriamente condição, mais do que fundamento, para ser precisamente fonte e conteúdo de onde emana, inclusive, a racionalidade como momento do ser vivente humano. Esse modo de realidade do ser vivente humano revela uma vida desde o corpóreo cerebral até a subjetividade consciente, autoconsciente, autônoma, livre e responsável pela própria vida (caso contrário, em contradição performativa, negaria a fonte e o conteúdo da própria vida).

Portanto, a vida como modo de realidade não é uma idéia, um conceito, uma definição, nem mesmo umá substância, uma pura racionalidade pensante, uma ação comunicativa ou um argumento. Dussel (2001, p.118), ao expor o tema, afirma que:

La "vida humana" no tiene como referencia a un universal abstracto, a un concepto de vida o a una definición. Es la "vida humana" concreta, empírica, de cada ser humano. Es la vida que para vivirse necesita comer, beber, vestirse, leer, pintar, crear música, danzar, cumplir ritos y extasiarse en las experiencias estéticas y místicas. Vida humana plena, biológica, corporal, gozosa, cultural, que se cumple en los valores supremos de las culturas - pero, como hemos dicho, no se identifica con los valores, sino que los origina, los ordena en jerarquías, de distintas maneras en cada cultura particular-. 
Por isso, a vida humana como critério fonte orienta as ações em geral, razão pela qual nenhum sistema ou subsistema (como é o caso do subsistema direito) pode deixar de ter como conteúdo a própria vida humana concreta de cada sujeito.

Portanto, o marco de referência é a vida humana. No plano mais concreto, o importante é a produção, reprodução e desenvolvimento da vida do sujeito. Essas são as três determinações centrais. O sujeito humano em comunidade precisa ter objetivamente satisfeitas certas condições que servem de mediações adequadas para viabilizar as determinações mencionadas. Condições essas que, se não forem levadas em conta, acarretam negações a aspectos da vida e no limite fatalmente levam à morte (negação do critério fonte e da condição de possibilidade). Trata-se da originária e genuína vulnerabilidade da vida do sujeito. De fato:

A vida sobrenada, em sua precisa vulnerabilidade, dentro de certos limites e exigindo certos conteúdos: se a temperatura da Terra sobe, morremos de calor; se não podemos beber devido a um processo de seca - como acontece aos povos subsaarianos - morremos de sede; se não podemos alimentar-nos, morremos de fome; se nossa comunidade é invadida por outra comunidade mais poderosa, somos dominados (vivemos, mas em graus de alienação que vão desde uma vida quase animal até à própria extinção, como no caso dos povos indígenas depois da conquista da América). A vida humana impõe limites, fundamenta normativamente uma ordem, tem exigências próprias. (DUSSEL, 2000, p.131)

Essa vulnerabilidade ameaça constantemente os momentos da produção, reprodução e desenvolvimento da vida concreta do sujeito. O momento da produção da vida humana inclui desde os níveis vegetativo ou físico até as funções superiores da mente, esta na sua consciência, autoconsciência, linguagem, valores, liberdade e assim por diante. A produção da vida é um ato cotidiano do sujeito, na relação cultural intersubjetiva e comunitária e, por isso, um processo histórico permanente (necessito de condições materiais - de conteúdos - para produzir neste e em cada instante a própria vida - desde. comer, respirar, vestir, incluindo a produção da vida com respeito aos instintos do prazer etc., o que é tudo desde já um ato subjetivo e intersubjetivo comunitário ao mesmo tempo, até as mais coletivas, complexas e sofisticadas criações culturais).

$\mathrm{O}$ momento da reprodução da vida humana, embora tenha o instante de uma autopoiese subjetiva - o que só é possível considerado o fenômeno de maneira abstrata -, é o momento das instituições e dos valores culturais, na condição de mediações necessárias e adequadas para a continuidade da vida do sujeito que reproduz a si mesmo no simples (complexo!) fato de viver, mas viver que é institucional, cultural e social (respiro ar, ato bio-subjetivo do sujeito em sua autopoiese, mas, ao mesmo tempo, respiro o ar desta específica cidade ou campo onde vivo, situação socioambiental e cultural intersubjetiva). E por ser intersubjetivo, o momento $d a$ reprodução contém o nível afetivo e pulsional, desde a espontaneidade libidinal até a complexidade institucional da disciplina e repressão do superego. De algum modo, trata-se do outro que a razão, base material libidinal composta pelos instintos de autoconservação e pelos instintos do prazer, referidos à satisfação das necessidades físicas, até a erótica humana propriamente dita. A reprodução da vida exige o momento 
formal da intersubjetividade - validade com relação aos instintos de autoconservação na segurança institucional.

E por fim, importa o momento do desenvolvimento da vida humana no quadro das macro e microestruturas da sociedade. O desenvolvimento histórico deixou lugar para a construção do humano para além de um mero crescimento natural. Assim, o sistema que em sua reprodução impede o desenvolvimento humano deverá ter na razão crítica a exigência de sua transformação. O próprio instinto do prazer - instinto de vida - desinibe e permite o desenvolvimento da vida, do sistema cognitivo e afetivoavaliativo humano - aparelho cerebral e psíquico - e das instituições históricas, com o objetivo de afirmar a subjetividade e não de negá-la (a negação como fato empírico inegável situa-se categorialmente no nível da defecção - defecção no viver (depressão ou morte), no prazer (patologia) e no poder (dominação institucional). Porém, diante da existência real, empírica e massiva de subjetividades negadas - carência de vida em alguma ou algumas dimensões da existência -, desde a exclusão e exploração do trabalho até ao analfabetismo de adultos e crianças, o desenvolvimento passa a ser um momento necessário da vida humana. Momento que instaura, inequivocamente, um direito subjetivo legítimo, com exigência de efetividade, intrínseco ao critério fonte anunciado: a vida concreta de cada sujeito como modo de realidade, sendo que aqui esse modo de realidade consiste na negação de vida em algum grau da subjetividade, por isso, categorialmente, subjetividade negada, na determinação específica do desenvolvimento.
Nesse contexto argumentativo, a vida humana - critério-fonte - não aparece propriamente como um direito. Como no caso de ter "direito à vida", por exemplo. Trata-se de um nível mais abstrato. Nesse sentido, a vida não é um direito, mas fonte de todos os direitos.

É esse o critério exposto em seus três momentos centrais que nos conduz ao princípio que é o crítico princípio da obrigação de produzir, reproduzir e desenvolver a vida humana concreta de cada sujeito em comunidade.

\section{A ÉTICA FILOSÓFICA}

A normatividade do princípio geral anunciado tem diversos desdobramentos nos distintos campos do ético, do político e do jurídico. Nessa ordem de compreensão, os princípios normativos éticos, desde logo, se constituem nas condições de possibilidade do agir ético, ou precisamente, eles são o momento essencial do ético. Os princípios normativos políticos são o momento essencial do político, e os princípios normativos do jurídico, o momento essencial do direito. Os princípios - nos diferentes campos - são pressupostos, condições intrínsecas - porque operam implicitamente - constitutivas da existência originária do campo ético, político e jurídico. Rosa Luxemburgo (1990, p.118) auxilia na definição do tema:

O sinal distintivo do oportunismo era, na altura, a hostilidade à "teoria". O que é natural, porque a nossa "teoria" - quer dizer, os princípios do socialismo científico - limitam firmemente a ação prática em relação aos objetivos visados, aos meios de luta e, por fim, ao modo da própria luta. 
Também os que só procuram resultados práticos têm um pendor natural para reclamar liberdade de manobra, quer dizer, separar a prática da "teoria", torná-las independentes.

Os princípios são necessários nessa condição: estabelecer marcos estritos, firmes, bem sólidos para a atividade prática, tanto no que se refere aos fins a alcançar como aos meios de luta utilizados, e, por fim, aos modos de luta. Sem o sentido da orientação dos princípios a prática fica entregue, ao que parece, à exclusiva lógica do êxito, definido pelo critério da operabilidade que é tecnológico (LYOTARD) e, por isso, não é pertinente para se julgar o verdadeiro e o justo. Rosa Luxemburgo mostra que nos três níveis da razão estratégico-instrumental modos, meios e fins - a ação deve ser orientada por um conjunto de princípios que impõe limites à atividade prática e indica um sentido de direção. Não é qualquer ação que pode realizada, não é qualquer meio que pode ser utilizado, nem qualquer fim escolhido, mas só aquela que for possível factível -, segundo a normatividade dos princípios em conjunto.

A complexidade do tema da fundamentação principiológica, não-metafísica, apresenta níveis de abstração distintos. No campo ético encontra-se o primeiro grau de abstração com os princípios éticos implícitos, os quais merecem ligeira menção.

Em primeiro lugar, a Ética filosófica, como em geral é vista, ocupa-se da reflexão sobre os atos bons ou maus. Para a Ética da Libertação, no entanto, esse é um objeto impossível porque, em última análise, os efeitos de um ato perduram no tempo e devem ser considerados também a longo prazo. Não é possível prever todos os efeitos de um ato, o que torna impossível a tarefa de sua avaliação em termos de bondade ou maldade. Diante disso, a reflexão da Ética da Libertação ocupa-se das condições universais $\mathrm{da}$ constituição do ato (norma, micro e macroestrutura social, instituição e sistema de eticidade etc.), considerados na perspectiva de sua bondade. Dessa maneira, a Ética estuda as condições universais da constituição de toda ação concreta e contingente, vista na perspectiva da pretensão de bondade. As condições universais servem de fundamentação ${ }^{5}$ dos atos concretos com honesta pretensão de bondade.

Em segundo lugar, a pretensão de bondade de um ato se verifica quando cumpridos os três princípios: momento material de verdade prática; o momento formal de validade consensual; e o momento da factibilidade da razão instrumental, na condição de mediações necessárias para a produção, reprodução e desenvolvimento da vida humana, sem deixar de levar em conta os efeitos negativos, mesmo os não intencionais.

Não custa lembrar, no entanto, da necessidade de os princípios éticos estarem determinados nos diversos campos e níveis concretos da erótica, da pedagógica, da econômica, da técnica, do jurídico, da política, e assim por diante. Pois, a ética não se concretiza no ético. Afinal, somos éticos ou não em cada um dos campós de nossa atuação prática cotidiana.

No conjunto dos princípios, o momento material é um dos princípios que têm a vida humana como conteúdo. A reflexão recai sobre

5 No sentido de fundamentação: fundamento e fonte - marco firme - de onde algo parte. 
o conteúdo de toda ação. A vida humana que não é mera sobrevivência - nos diversos momentos da produção, reprodução e desenvolvimento tem a necessidade de certos conteúdos, no nível físico-biológico, histórico-cultual, econômico-político, ético-estético, político-social, místicotranscendental, porque não é apenas vida, mas vida humana - sempre vista, por ser humana, como digna. Certos contelídos, que vão desde a necessidade de alimentos, casa, segurança, liberdade, valores, identidade cultural e soberania, até as mais sofisticadas manifestações da criatividade cultural, são exigidos porque a vida está impregnada de necessidades materiais.

A insuficiência do aspecto material antes anunciado requer o princípio formal de validade, pois a norma ou sistema a ser executado na ação não decorre direta e imediatamente do princípio biológicoinstintivo (como no animal) no modo de realidade do sujeito ético. O princípio que co-determina o princípio material é refundado, hoje, como princípio da racionalidade discursiva prático-intersubjetiva, para que as decisões de conteúdo, ainda que verdadeiras, ganhem validade democráticointersubjetiva. Esse momento formal (DUSSEL, 2000, p.169-236) é, agora, a nova "astúcia da vida" - e tem na razão comunicativa sua forma por excelência. Assim, o tema da validade, com pretensão de universalidade, passa da ordem da fundamentação subjetiva para a fundamentação intersubjetiva, desde o núcleo básico da razão comunicativa habermasiana. Nessa condição, articulação dialética entre os dois momentos mostra que a pretensão de verdade é já sempre intersubjetiva, e toda pretensão de validade intersubjetiva tem como referência um conteúdo. A dialeticidade intensa, entre os dois momentos, indica que não há validade sérià sem pretensão de verdade (material) e não há verdade sem pretensão de validade (formal intersubjetiva).

A bondade não se completa na verdade e validade. A bondade é mais do que a verdade e a validade. Exige um princípio ético a mais, que é o âmbito da factibilidade que diz respeito à possibilidade ou impossibilidade ${ }^{6}$ do "objeto" prático. É o momento em que o verdadeiro e o válido são julgados em sua factibilidade pela razão instrumental e estratégica, nos diversos níveis de possibilidade-e impossibilidade. ${ }^{7}$ Nessa concepção, o critério de factibilidade exige que se leve em conta as condições de possibilidade objetiva (materiais e formais, empíricas, técnicas, econômicas, políticas, jurídicas etc.) para que o ato seja efetivamente possível. Esse princípio tem na razão estratégico-instrumental a mediação que se ocupa da "factibilidade" eficaz da ação humana. A necessária razão situada na esfera

${ }^{6}$ Franz HINKELAMMERT define o princípio da impossibilidade empírica (1988, p.170): "é impossível o conhecimento perfeito de todos os fatos da relação social humana interdependente. Essa impossibilidade vale tanto para cada homem como para qualquer grupo humano e, por conseguinte, para toda instituição humana."

7 O princípio da factibilidade considera os diversos níveis do possível, desde: a impossibilidade lógica; a possibilidade lógica, porém impossibilidade empírica; a possibilidade empírica, porém impossibilidade técnica; a factibilidade técnica, porém impossibilidade econômica; a possibilidade econômica, porém impossibilidade ética ou jurídica; a possibilidade ética ou jurídica ao princípio de operabilidade; e assim por diante. 
da relação "meios-fins", portanto, não só é útil como insubstituível. Terá, no entanto, que estar sobredeterminada pelas exigências de verdade prática do momento material e de validade intersubjetiva. Agora, na dialeticidade dos três princípios éticos, os momentos material e formal subsumem o critério da factibilidade, sobredeterminando-o, com o que se determina o âmbito do que se pode fazer técnico-economicamente, considerado o horizonte (a) do que é eticamente permitido fazer e (b) do que se deve fazer necessariamente.

Dessa maneira, a pretensão de bondade, orientada principiologicamente, exige do agente que o ato para ser bom tem de ser válido, verdadeiro e possível. Porém, a contingência de todo ato faz com que o agente cometa diariamente atos injustos. No entanto, a pretensão de bondade pressupõe a finitude do ato, e, os conseqüentes e inevitáveis, efeitos negativos. Essa limitação do agente instaura a necessidade de uma dimensão crítica que permita corrigir permanentemente o ato e os efeitos negativos produzidos. À ética filosófica cumpre ocupar-se dos princípios críticos (o momento da crítica material, da crítica forma e da crítica factível) que venham a fundamentar e orientar criticamente a ação do sujeito.

\section{A FILOSOFIA POLÍTICA}

No primeiro grau de abstração está o campo ético - com seus princípios éticos implícitos, ligeiramente mencionados. De outra parte, em grau menos abstrato está o campo político, também com princípios políticos implícitos, e que metodologicamente subsume o nível anterior.
De fato, o ato político (que também pode ser uma norma, agora política, assim como a micro e macroestruturas, as instituições políticas, os partidos políticos etc.) têm determinações específicas. O campo político, como esfera pública, tem, como o ético, diversos níveis de generalidade. Esquematicamente, o primeiro é o nível dos princípios universais da Política; o segundo nível é o das mediações sistêmicas; e o terceiro é o nível da ação política concreta. Acentuarei, um pouco mais, o primeiro nível.

Esse primeiro é o nível abstrato dos princípios universais da Política como tal. Desde já cabe destacar a lógica segundo a qual o campo político subsume o campo ético em seu núcleo principiológico.

Nesse nível mais abstrato, a arquitetônica de uma filosofia política crítica proposta por Dussel (2001, p.148), fica assim definida:

La Política se ocupa a) de las condiciones o principios de la producción y reproducción de la vida de la comunidad política (en un nivel ecológico-económico, en un sentido amplio (como nivel de los contenidos de la razón política práctico-material); b) de las condiciones o principios de los procedimientos normativos de legitimidad consensual (en el nivel dêl Principio Democrático en todos sus aspectos, como regulación de la participación pública y simétrica de los afectados, ámbito de la razón discursivo-política); c) de las condiciones o principios de la factiblilidad política en la efectuación de los medios y fines de la acción concreta (principios que rigen la lucha por la hegemonía y en ejercicio del Poder político, nivel de la razón estratégico-instrumental propiamente dicha).

Como fica claro no texto citado, também na Política são considerados os três princípios afirmativos dessa complexa racionalidade.

A primeira determinação da racionalidade política é a material. Seu conteúdo fundamental 
é o da exigência de produzir, reproduzir e desenvolver a vida humana em comunidade e a vida de toda a humanidade. Portanto, como fundamento - 'marco' - inicial a racionalidade política é prático-material. Nas exigências deste princípio, o modo de realidade do sujeito, faz com que limites rígidos sejam observados, agora pela ação política, e certos conteúdos são exigidos, tais como necessidades concretas para tornar factível a vida em seu momento material, conteúdos sem os quais a vida resta ameaçada, com negações permanentes. Como na ética, da ação política - por meio de suas mediações específicas e particulares -, exige-se o cumprimento do imperativo material do político. É nessa lógica que o ético é subsumido no político, princípio material orientador de conteúdos.

A segunda determinação da racionalidade política é a formal. O critério orientador, nesta parte, é o "Princípio-Democracia" (Habermas). A racionalidade política livre deve alcançar a validade - legitimidade formal - pela participação simétrica dos cidadãos como sujeitos autônomos na comunidade de comunicação política. ${ }^{8} \mathrm{O}$ que pretendo dizer é que o princípio material do exercício da razão política não se pode efetivar sem a

\footnotetext{
${ }^{8}$ A tese é formulada por Dussel (2001, p.50-51) nos seguintes termos: "La ratio política livre, discursiva, procedimental o democráticamente (formaliter) deve alcanzar validez (légitimidad formal) por la participación pública, efectiva, libre y simétrica de los afectados, los ciudadanos como sujetos autónomos, em ejercicio de la plena autonomía de la comunidad de comunicación política, que por ello es la comunidad intersubjetiva de la soberanía popular, fuente y destino del derecho, cuyas decisiones tienen por ello pretensión de validez o legitimidad política universal."
}

mediação da razão político-discursiva, nos tempos atuais. Parece ser esse o caminho indicado pelas novas teorias contratualistas, como é o caso da teoria de John Rawls, da teoria de Habermas/Apel, que procuram renovar o tema na concepção da racionalidade comunicativa intersubjetiva dialógica. A razão comunicativa, regida pelo princípio democrático, passa a ser o critério ou idéia reguladora da produção discursiva de consensos. Nesse conceito, a comunidade, como novo ponto de partida, passa à condição de fonte criadora do direito, ao produzir seu próprio direito, e, ao mesmo tempo, como destinatária dele.

Esse momento formal, no entanto, deve estar articulado dialeticamente com a instância material, para evitar o risco de um formalismo reducionista do Princípio Democrático. A validade formal não ganha legitimidade suficiente no (mero) procedimento. Os conteúdos materiais da política exigem que a validade formal (procedimental discursiva) tenha em vista a produção, a reprodução e o desenvolvimento da vida humana concreta de todos e de cada sujeito que vive em comunidade. Pois, ina periferia e semiperiferia do mundo, a negação da vida exige - juízo descritivo empírico com inegável pretensão de verdade, só mesmo refutável pelo cínico - antes de qualquer outro nível, a reprodução material/ econômica/ecológica da vida como momento de afirmação (negação da negação). Nessa concepção geral, em tese, todo ato que pretenda produzir, reproduzir e desenvolver a vida humana em sociedade deve ser decidido, politicamente, com a mediação formal do princípio democrático intersubjetivo discursivo. É aqui que o ético e o político se 
entrelaçam em dois sentidos. Antes, porque o momento formal da Política subsume o momento formal da Ética. E depois, porque o momento formal da Política - a validade intersubjetiva - subsume o momento material da Política - a verdade material. Assim, dá-se o encontro da verdade e da validade políticas.

A terceira determinação da racionalidade política é a estratégico instrumental. Precavido com o princípio da factibilidade, como mediação insubstituível, a razão política deve atuar tendo em conta as condições, definidas nos diversos níveis de possibilidade, já anunciados no princípio ético. Atento a tais níveis, as mediações políticas podem ter pretensão de factibilidade e/ou de êxito político. Estará, assim, a razão política estratégica e instrumental - sobredeterminada pelos princípios da razão política material e pela razão política discursiva.

Na lógica dos argumentos já apresentados, é importante que a ação política (ato, norma, instituição etc.) tenha validade formal, é decisivo que o conteúdo seja verdadeiro (principalmente, nas exigências éticodeônticas referentes às necessidades básicas), mas é necessário, também, que seja factível para que a ação política seja ética. ${ }^{9}$

Nessas condições, toda mediação política (seja ela uma norma, ato, instituição ou sistema - o sistema jurídico, por exemplo,

\footnotetext{
${ }^{9}$ No campo político, os princípios anunciados e apenas anunciados, sem o devido desenvolvimento indicam o nível mais geral da abstração, pois eles não têm em vista ações concretas específicas, como seria o caso de examinar 'formas de governo', 'formas de democracia', 'formas de representação', 'organização partidária' e assim por diante. Esses temas estão numa esfera mais concreta daquela das teses.
}

um partido político, uma forma de governo) poderá ter pretensão de justiça política. Nessa factibilidade está certamente a determinação específica do Político. A ação política encontra em suas diversas frentes sua determinação especial. Demarcação que tem a racionalidade política como estratégicoinstrumental, e que se ocupa da "factibilidade" eficaz da ação política em particular.

Da mesma maneira como na Ética, a razão política estratégica deverá estar sobredeterminada pela razão política material (nos níveis concretos das exigências materiais para a reprodução da vida dos cidadãos) e articulada com a validade política (as mediações necessárias para a efetivação do princípio democrático - formas de governos, partidos, direito e outras). Com isso, a compreensão do Político fica ampliada, ao não reduzi-lo à determinação da dimensão estratégica. Ainda assim, deve-se levar em conta os inevitáveis efeitos negativos da ação, sobre os quais deve haver responsabilidade política, orientada eticamente. É a dimensão da crítica política.

\section{A FILOSOFIA JURÍDICA TRANSMODERNA}

O segundo nível de generalidade da Política é o das mediações sistêmicas. É por meio das mediações que se cumprem institucionalmente as condições universais acima apresentadas:

El nível B es el de las mediaciones sistémicas. Allí se cumplen institucionalmente las condiciones universales por meio de sistemas concretos. En primeiro lugar, a) los sistemas materiales ecológico-económicos; en segundo lugar, b) los sistemas formales procedimentales del ejercicio ligítimo del Poder político (donde, 
como veremos, entra todo el sistema del derecho); y, por último, c) el sistema del Estado, como macro-institución del ejercicio monopólico del Poder político en última instancia, al servicio de los dos aspectos ya indicados (a y b). (DUSSEL, 2001, p.148)

Um terceiro nível integra o político na concepção de Dussel (2001, p.148): “Hay todavia un nível $\mathrm{C}$, el de la acción política concreta; es donde se expone toda una teoría de dicha acción, de la lógica de la lucha política por la hegemonía, la manera del ejercicio del Poder y el uso monopólico de la coaccción para hacer respetar el "estado de derecho' en vista del bien común."

As citações transcritas completam o desenho do político nos diversos níveis de generalidade (níveis $\mathrm{A}, \mathrm{B}$ e $\mathrm{C}$, segundo Dussel). Esse quadro permite que se avance na direção do campo jurídico.

Com efeito, da mesma maneira como os campos ético e político indicados, o campo jurídico, também, situa-se nos três níveis até agora mencionados: o primeiro, nível dos princípios universais e abstratos; o segundo, nível particular das mediações sistêmicas, e o terceiro, o nível da ação concreta.

Cada um desses três níveis de generalidade do Jurídico merece aprofundamento maior. No entanto, aqui os níveis restam apenas indicados, para encaminhar a reflexão nos temas específicos da dinâmica da transformação do direito ante os novos direitos.

5.1 A crítica jurídica: os efeitos negativos, transformação jurídica e os novos direitos

O processo de transformação crítica complexo tema que envolve a necessidade de novos princípios, agora na parte da negatividade, por isso sempre princípios críticos que são os princípios da crítica material, da crítica formal e do novo possível.

A transformação crítica é necessária em todos os campos, e cabe à ética filosófica se ocupar da reflexão no campo ético, à filosofia política no campo político, e cabe à filosofia jurídica lidar com o campo jurídico (nos níveis já mencionados: dos princípios universais e abstratos; das mediações sistêmicas; e da ação concreta). Interessam nesse momento os efeitos negativos não intencionais produzidos pelo sistema jurídico vigente.

$\mathrm{Na}$ ordem das idéias até agora apresentadas, isso significa retornar ao critério-fonte - a vida concreta como modo de realidade - e que conduz ao princípio crítico da obrigação de produzir, reproduzir e desenvolver a vida humana concreta de cada sujeito em comunidade, através da mediação sistêmica que é o sistema direito. A impossibilidade de viver em algum nível - viver dignamente -, manifestada negativamente em algum aspecto material da vida, revela igualmente uma negatividade formal, que pode ter sido produzida pelo direito ou não reconhecida pelo sistema do direito vigente. A crítica jurídica passa a ser necessária como momento negativo que descobre a injustiça (na positividade), agora desde a negatividade formal (algum aspecto material da vida é negado formalmente). Assim, o conceito de justiça surge desde o conceito de injustiça (Hinkelammert). Esse conceito permite dizer que a injustiça consiste em não reproduzir e desenvolver a vida humana, a começar pelas condições materiais - econômico-ecológicas, por exemplo. Pode-se derivar, também como contra-imagem, que a justiça é produzir as condições materiais da vida, conservando, 
porém, as suas fontes originais: a natureza e o ser humano trabalhador. Assim, a injustiça está nos mais diversos níveis de negação da vida concreta dos sujeitos. E a transformação do sistema direito deve estar orientada pelo critério específico, de que a realização da justiça está na negação dessa negação (dialética) desde a positividade (momento analético, os novos direitos, ou então, o direito no qual caibam todos, por exemplo, quando os excluídos do acesso à Justiça são a referência). A exigência de justiça surge, portanto, da negatividade. E, certamente, uma das importantes determinações dessa negatividade é jurídica. Está na esfera dos direitos - dos direitos negados -, negação, portanto, no campo jurídico. Por um lado, essa negatividade é efeito da perversidade da lógica global do sistema mundo nesse momento histórico, por outro, no entanto, é efeito específico da lógica de cada subsistema: efeitos negativos do subsistema jurídico.

Nesse sentido geral e global, é precisa a informação trazida por Dussel (2003, p.52), quanto ao sentido da perversidade da lógica global do mundo:

A los 500 anos del comienzo de la Europa moderna, leemos em Informe sobre el desarrollo humano 1992 de las Naciones Unidas que el $20 \%$ más rico de la humanidad (principalmente Europa occidental, Estados Unidos y Japón) consume el $82 \%$ de los bienes de la tierra, y el $60 \%$ más pobre (la 'periferia' histórica del 'Sistema-mundial') consume el $5,8 \%$ de dichos bienes. Una concentración jamás observada en la historia de la humanidad! Una injusticia estructural nunca sospechada en la escala mundial! No es este acaso el fruto de la Modernidad o del Sistema mundial que inició la Europa occidental?

Mas, não parece menos verdade a situação específica do sistema direito, quando examinado sob o ponto de vista dos efeitos negativos produzidos, mesmo que não intencionais. Nesse sentido específico e local, cabe lembrar a situação descrita por Faria (1998, p.100), ao comentar os efeitos negativos produzidos pela atuação de um determinado campo, como é o caso do sistema jurídico:

Veja-se, como exemplo, a violência no campo: dos 1.681 assassinatos de trabalhadores rurais em função de conflitos no campo, ao longo dos últimos 28 anos, apenas 26 chegaram a ser julgados, dos quais somente 15 deram margem a condenação. Veja-se, também, o caso da exploração do trabalho de crianças: embora a Constituição proíba o trabalho de menores de catorze anos, as estatísticas governamentais registram a presença de três milhões de crianças com essa idade na economia formal e informal. Veja-se, igualmente, o caso da violência policial: apesar do reconhecimento do "devido processo legal", pela Constituição, a ação repressiva dos organismos policiais na maior cidade brasileira é responsável pela morte de uma pessoa a cada seis horas; desde 1989 e 1990, a média tem sido de quatro mortes ao dia, ou seja, 120 mortes por mês e 1.460 mortos por ano - média essa três vezes superior à registrada entre $1983 \mathrm{e}$ $1987 ;(\ldots)$.

(...) A extensão e a regularidade dessas violações dos direitos consagrados pela Constituição são reveladoras da ineficiência do Judiciário, como aplicador das normas e fiscalizador do império da lei. (...).

A conclusão, evidentemente, não poderia ser outra: a ineficácia judicial conduz a uma crise de legitimidade do Judiciário, decorrente tanto de fatores internos, como o anacronismo de sua estrutura organizacional, quanto de fatores externos, em face da insegurança da sociedade em relação à impunidade, à discriminação e à aplicação seletiva de leis.

\section{A transformação crítica do sistema} direito (negação de parte da positividade vigente) requer um conceito de justiça - que absorva a injustiça da negatividade -, o que 
é possível historicamente nos momentos em que a necessidade de afirmação da vida é conduzida pela comunidade das vítimas. Uma das mediações específicas do direito, neste caso, é a de possibilitar o exercício efetivo de incorporação de novos direitos. Essa transformação é possível quando os atores que sofrem as negações tomam consciência de um novo direito que se produz na história concreta da comunidade das vítimas, que ganha legitimidade intersubjetiva, porque há negação material da vida, com pretensão de nova legalidade.

Dessa maneira, os novos direitos, orientados pelo critério de justiça mencionado, passam a ser necessários, pois visam à afirmação de direitos daqueles que têm uma dimensão da vida negada. Refiro-me àqueles que se encontram na condição de "semdireitos" (ou vítimas do sistema direito vigente). Portanto, é este o espaço dos novos sujeitos de direitos, compreendidos a partir da racionalidade negada, na perspectiva antropocêntrica, ótica do paradigma da vida concreta como modo de realidade (aqui o modo é o da "vida negada"), no horizonte do projeto transmoderno.

Porém, o sistema direito não se transforma abruptamente, a não ser nos casos das revoluções extremas. A transformação do direito é bastante lenta, em geral. O desenvolvimento histórico mostra que há uma dinâmica de conservação, negação e inovação de direitos, o que permite bem compreender o movimento e o lugar dos novos direitos. É certo que o direito é um fenômeno histórico, portanto, produto de uma determinada época. Porém, na parte que toca à dinâmica própria do direito, é possível observar que na transformação (a) um núcleo de direitos tem uma permanência para além da época que os originou; (b) outros direitos desaparecem juntamente com a época que os criou; enquanto os (c) novos direitos passam a integrar o sistema vigente. Diante dessa dinâmica, principalmente a parte que diz respeito (c) aos novos direitos interessa especialmente à racionalidade jurídica crítico-libertadora.

Surge agora o momento da razão instrumental, movimento concreto da práxis que opera no espaço que vai desde a tomada de consciência dos novos direitos, por parte dos movimentos sociais, até a efetiva institucionalização. A dialética se dá entre o direito vigente e os novos direitos insurgentes. O tempo que transcorre nesse enfrentamento indica um tríplice processo, assim descrito:

1) por una parte, de "deslegitimación" del derecho vigente que comienza a transformarse en derecho "antiguo"; 2) por otra, de "legitimación" del nuevo derecho que desde una posición de no-vigencia y no-legítimo pasará lentamente a una situacion de legitimidad triunfante; 3) por último, se producirá la derogación de ciertos aspectos del derecho antiguo claramente contradictorios con el nuevo derecho. El proceso de deslegitimación es simultáneo y contrario al de legitimación del nuevo derecho. Es decir, el proceso de legitimación originaria parte inevitablemente de la ilegalidad ilegítima, así como el proceso de deslegitimación deberá ir reconociendo, ante la lucha por el reconocimiento de los sin-derechos, la ilegalidad creciente de su antigua legalidad. (DUSSEL, 2001, p.154-155).

A relação entre o direito vigente e o novo direito, bem como o direito futuro, não é meramente mecânica. Não se trata de possível justaposição ente o núcleo do direito que permanece e o novo direito. A dialética é de tensão e de conflito, e é nela que se opera a reconstrução do sistema jurídico. É nessa dinâmica que os "sem-direitos- 
ainda" começam a luta pela inclusão de novos direitos no sistema de direito vigente, orientado pelo critério crítico dos dissensos (agora novos consensos - obtidos intersubjetivamente na comunidade das vítimas), fonte de legitimidade. Por fim, a dialética que movimenta a reconstrução do sistema jurídico no entrecruzamento do direito que permanece com o direito insurgente não pode se reduzir à dialética entre conteúdo e forma, mas deve incluir a dialética entre afirmação e negação, o que faz com que a racionalidade jurídica críticolibertadora seja material e negativa.

Dessa maneira, tendo em conta a lógica das idéias exposta, creio que a função específica do sistema direito seja dupla: de um lado, a função é de conservação onde a vida está afirmada; e, de outro, a função é de transformação onde a vida está negada.

Afinal, a arquitetônica aqui sugerida merece um capítulo todo próprio e específico, na perspectiva de uma racionalidade jurídica libertadora, o que é raro na Filosofia do Direito.

\section{REFERÊNCIAS}

CERUTTI GULDBERG, H. Filosofia de la liberación latinoamericana. México: Fundo de Cultura Económica, 1983.

DUSSEL, E. D. Ética da libertação - na idade da globalização e da exclusão. Petrópolis: Vozes, 2000.

DUSSEL, E. D. Hacia una filosofia política crítica. Bilbao: Desclée de Brouwer, 2001.
DUSSEL, E. D. Europa, modernidad y eurocentrismo. In: La colonialidad del saber: eurocentrismo y ciências sociales - perspectivas latinoamericanas. Buenos Aires: Clacso, 2003.

FARIA, J. E. (Org.). Direitos humanos, direitos sociais e justiça. São Paulo: Malheiros, 1998.

FORNET-BETANCOURT, R. (Org.). Filosofia para la convivencia - caminos de diálogos norte-sur. Sevilha: Ed. MAD, 2004.

HABERMAS, J. Direito e Democracia: entre facticidade e validade. Rio de Janeiro: Tempo Brasileiro, 1997. 2v.

HINKELAMMERT, F. J. Crítica à Razão Utópica. São Paulo: Paulinas, 1986.

HINKELAMMERT, F. J. Pensar em alternativas: capitalismo, socialismo e a possibilidade de outro mundo. In: PIXLEY, J. (Coord.). Por um mundo diferente: alternativas para o mercado global. Petrópolis: Vozes, 2003. p.9-49.

LANDER, E. (Compilador). La colonialidad del saber: eurocentrismo y ciências sociales perspectivas latinoamericanas. Buenos Aires: Clacso, 2003.

LYOTARD, Jean-François. A condição pósmoderna. 5. ed. Rio de Janeiro: José Olympio, 1998.

LUDWIG, C. L. Da ética à filosofia política crítica na transmodernidade: reflexões desde a filosofia de Enrique Dussel. In: FONSECA, R. M. (Org.). Repensando a teoria do-estado. Belo Horizonte: Fórum, 2004. p.283-325.

LUXEMBURGO, R. Reforma Social ou Revolução?. 2. ed. São Paulo: Global, 1990.

MANCE, E. A. Uma introdução conceitual às filosofias de Libertação. In: Revista Libertação Liberación, Ano I, n. 1, 2000. p.25-80.

SALAZAR BONDY, A. Existe una filosofía de nuestra America? México: Ed. Siglo Veintiuno, 1968.

SANTOS, B. de S. A crítica da razão indolente: contra o desperdício da experiência. São Paulo: Cortez, 2000. 